there will be 39,000 employees, compared to the 6,000 now working in the field. While USACA Board Chairman Bernard Meyer, who is executive vice president of the Norton Company, characterized most advanced ceramics activity as currently at the pilot stage, he and other officials there believe ceramic components will begin making their way into U.S. automobiles and trucks in the next two years.

USACA reinforced its support of current federal efforts, including those already existing at the Departments of Defense, Energy, and Commerce. "We applaud these efforts, and think their successes justify additional programs," said Savitz. "For example, it would be valuable to demonstrate ceramic gas-turbine engines and other ceramic components in automobiles and trucks and in aerospace applications." At the Defense Advanced Research Projects Agency, USACA is backing an insertion program whose purpose is to demonstrate advanced ceramics components in military systems.
Many private firms have good ideas that the government needs but hesitate to work with the government because they fear their ideas will be declared subject inventions, Savitz found. She noted that the government may indeed be cutting itself off from technologies critical to its needs.

USACA defines advanced ceramics as including a wide range of inorganic, nonmetallic materials "produced by new technologies." Advanced ceramics differ from conventional ceramic consumer goods, such as dinnerware and tiles, because of their greatly improved properties, the novelty of the processes used to produce them, and their applications. They are considered to have superior wear resistance, resistance to chemicals and high temperatures, and dimensional stability, and strength-to-weight ratios three times higher than metals. They are used in aerospace, environmental protection, automobile, defense, and electronics applications and even in bioceramics for artificial bone and teeth implants.

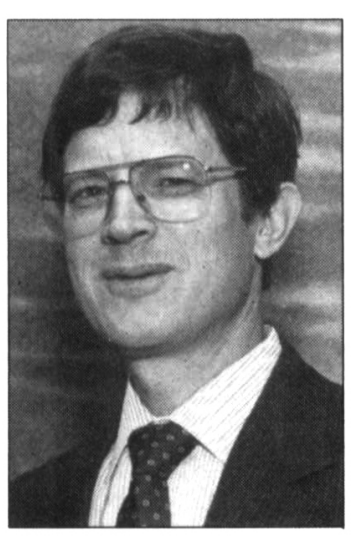

\title{
Robert Post Represents MRS in New Public Affairs Office
}

Robert L. Post, who recently completed his tenure with the White House Office of Science and Technology Policy (OSTP) and his position as executive director of the National Critical Materials Council, has been devoting a portion of his time for the fall quarter to the MRS Office of Public Affairs in Washington, DC. Post joined the OSTP under the Reagan administration and helped with the transition after the 1988 election. He has had broad experience with the materials-related activities of that office in addition to experience with the funding of materials and other technical fields at the Office of Management and Budget.

Post holds a PhD in geology from the University of California at Los Angeles and an MBA from Harvard University. After serving in the armed forces, he has been primarily associated with the governmental side of science and science policy.

Through the MRS BULLETIN, Post will keep MRS members informed of materials-related activities in Washington. He will also brief MRS officers on matters of concern to the Society on the Washington scene, as well as field government and press requests for information about MRS and materials science and engineering in general.

Post's efforts will also support the upcoming Washington Materials Forum, February 28-March 1, 1991, sponsored by MRS and several other societies. The forum will follow the Solid State Sciences Committee meeting on February 27 at the National Academy of Sciences, and will include a report on the Materials Science and Engineering Study's Regional Meetings. Post was instrumental in initiating the Regional Meetings and has participated in the process to this point. MRS looks forward to his assistance in spotlighting for science policymakers the importance of materials and of MRS's role in the materials community, and in providing for MRS members a clearer window on materials-related activities in Washington.

MRS Office of Public Affairs Washington, $D C$

\section{USACA's "Bridging the Gap Initiative" for Advanced Ceramics}

Point One: Create multiyear federal ceramic component demonstration programs that will support the domestic development, manufacture, purchase and in-use demonstration of advanced ceramic components and parts over a five-year period. They would target both civilian and military programs, including automotive, aerospace structural, aerospace propulsion, electronics, machine tools, additional weapons systems, component applications, and industrial process equipment. Point Two: Create Defense Production Act Title III advanced ceramics programs. These programs would take the form of purchase commitments (guarantees) to buy ceramic components produced by domestic advanced ceramics manufacturers for incorporation into various military systems.

Point Three: Create and expand investments in domestic advanced ceramics manufacturing science and technology programs aimed at demonstrating costeffective production and reproducibility of advanced ceramic components focused on specific requirements of endusers.

Point Four: Recognize the capital intensive nature of the advanced ceramics industry and promote industrialization in this area by allowing a more competitive return on advanced ceramic components purchased through the federal procurement system and by permitting first-year write-down of those new capital investments made by the advanced ceramics industry during a 10 year period.

Point Five: Provide tax incentives, such as government-funded rebates, for domestic advanced ceramic end-users who incorporate advanced ceramic components in products and demonstration programs during the next decade, so as to provide user "pull through" to the U.S. advanced ceramics industry.

Point Six: Mandate the vesting of technology rights in advanced ceramics to domestic advanced ceramic manufacturing contractors when they participate in R\&D, man-tech and demonstration programs on a costshared basis, in order to attract and promote the most commercially attractive and innovative technologies in these efforts. 


\section{THE BEST WAY TO GET AN ANGLE ON CRYSTALS.}

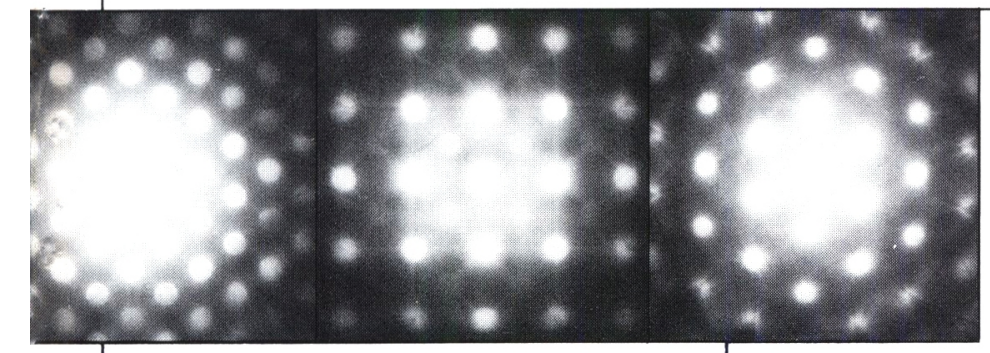

High resolution,

Please vist Booth No. 959-940 at the MAS

electron microdif-

fraction analysis

may require several

tilt angles.

If you need to determine elemental composition and molecular or atomic structure of crystals in minerals, metals, ceramics or polymers, our JEM-2010 is the best high resolution, analytical microscope for the job.

The JEM-2010 is a $200 \mathrm{kV}$ TEM with superior optics and high probe current. It is optimized for analytical performance oriented crystalline material in metal, mineral, ceramic or polymer matrices, the JEM-2010 offers $2.3 \AA$ resolution with a tilt angle of \pm 30 degrees.

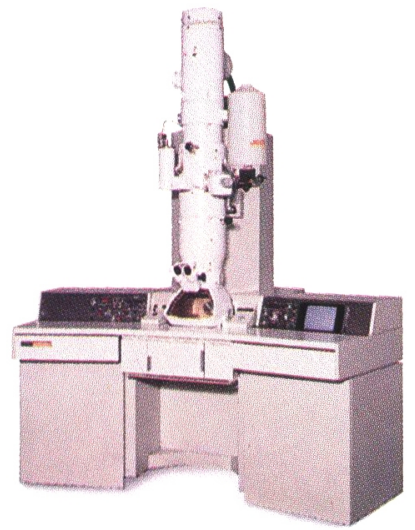

JEM-2010 Transmission Electron Microscope not only in the analytical configuration, but also in the ultra-high resolution configuration as well.

Equipped with EDS, the JEM2010 is capable of high sensitivity elemental analyses using probes as small as $10 \AA$ in diameter.

With its analytical pole piece, it offers $2.3 \AA$ resolution over $30^{\circ}$ of tilt and an $x$-ray collection angle of 0.13 stearadians. That is the best combination of analytical features of any instrument in the $200 \mathrm{kV}$ class.

But the JEM-2010 is more than an analytical microscope.

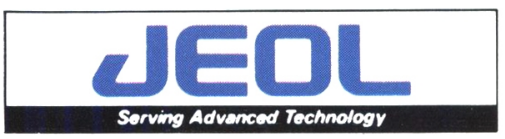
Show in Bosten, Nowember 28-30, 1989.

\section{Equipped with the inter-} changeable, high resolution pole piece, the JEM-2010 is also an ultra-high resolution microscope with $1.9 \AA$ resolution over $10^{\circ}$ of tilt and an $x$-ray collection angle of 0.07 stearadians.

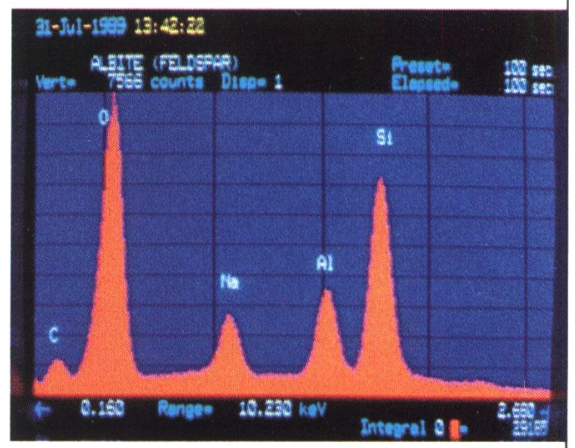

High sensitivity elemental analysis is possible with the addition of an EDS system.

Let us tell you more. Call (508) 535-5900. Or write JEOL USA, Inc., 11 Dearborn Road, Peabody, MA 01960. 

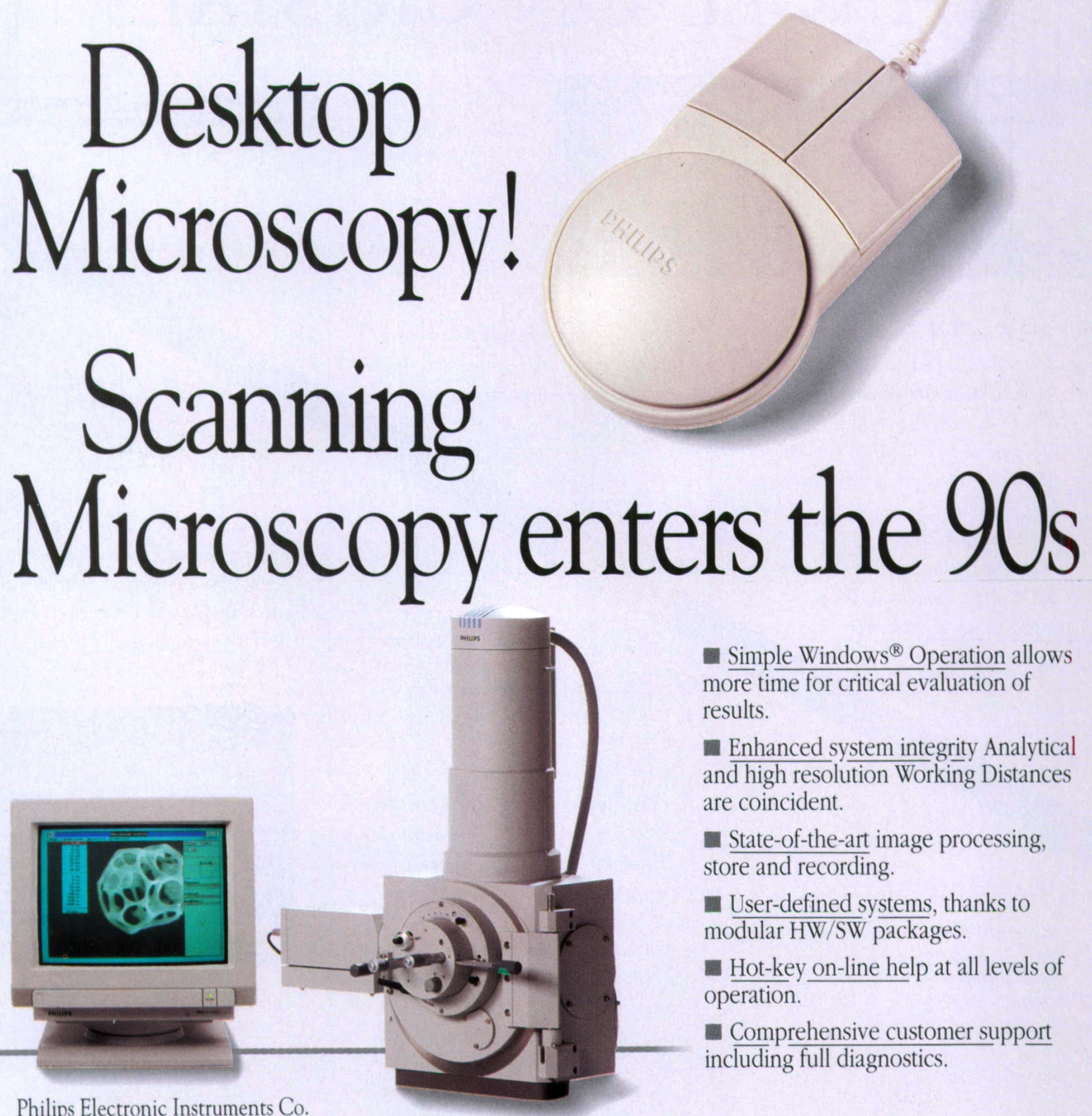

Philips Electronic Instruments Co.

85 McKee Drive

Please visit Booth No. 939-940 at the MRS

Mahwah, New Jersey 07430

Show in Boston, November 27-29, 1990.

Telephone Toll Free 1-800-32 32-PEI

THE XL SERIES SEMS.DESKTOP MICROSCOPY FROM PHILIPS 
Keeping pace with the increasing pace of change. Demands on materials researchers are growing exponentially. Yet, while the pace of change increases, there still isn't any more time in a day. And less room for error than ever.

South Bay Technology is the solution. We've helped keep research professionals just ahead of the pace of change since 1964.

SBT equipment, whether stock or custom design, brings you quickly and

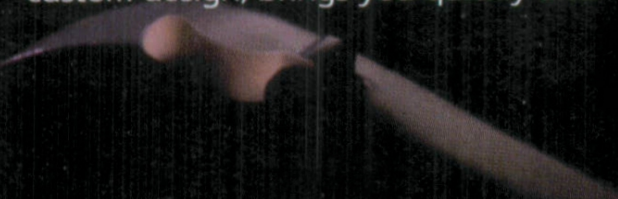

How to make light work of your toughest specimen preparation

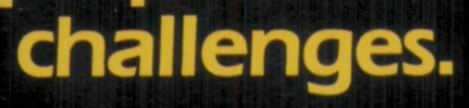

precisely through even the most delicate specimen preparation challenges. Precision wire saws and diamond wheel saws give you an as-cut surface that will substantially reduce post-cut preparation time, even with brittle or multilayered substrate materials.

Beyond that are the finest lapping and polishing fixtures, chemical polishers, TEM specimen preparation instruments, and metallographic equipment and supplies available. All can greatly reduce sample preparation time, and many complete their tasks with the option of continual unattended operation.
A one-step solution to the mounting time problem. We've also overcome the primary cause of lost time and damaged material. The SBT Universal Mount lets you bring a specimen through every step of the preparation process, without the hazards of remounting.

The result? Large damage-free surfaces are quickly and easily reached, even down to the level required for TEM observation of undisturbed atoms.

Information is power - and free

- from SBT. Find out more about how SBT can help you keep pace with the increasing pace of change. Complete the form below and mail it to SBT today. Or, for faster service, call us at (800) SBT-2233. We'll rush you information about the SBT equipment that really can make lighter work of your specimen preparation challenges.

Please visit Booth No. 16-17 at the MRS Show in Boston, November 27-29, 1990.

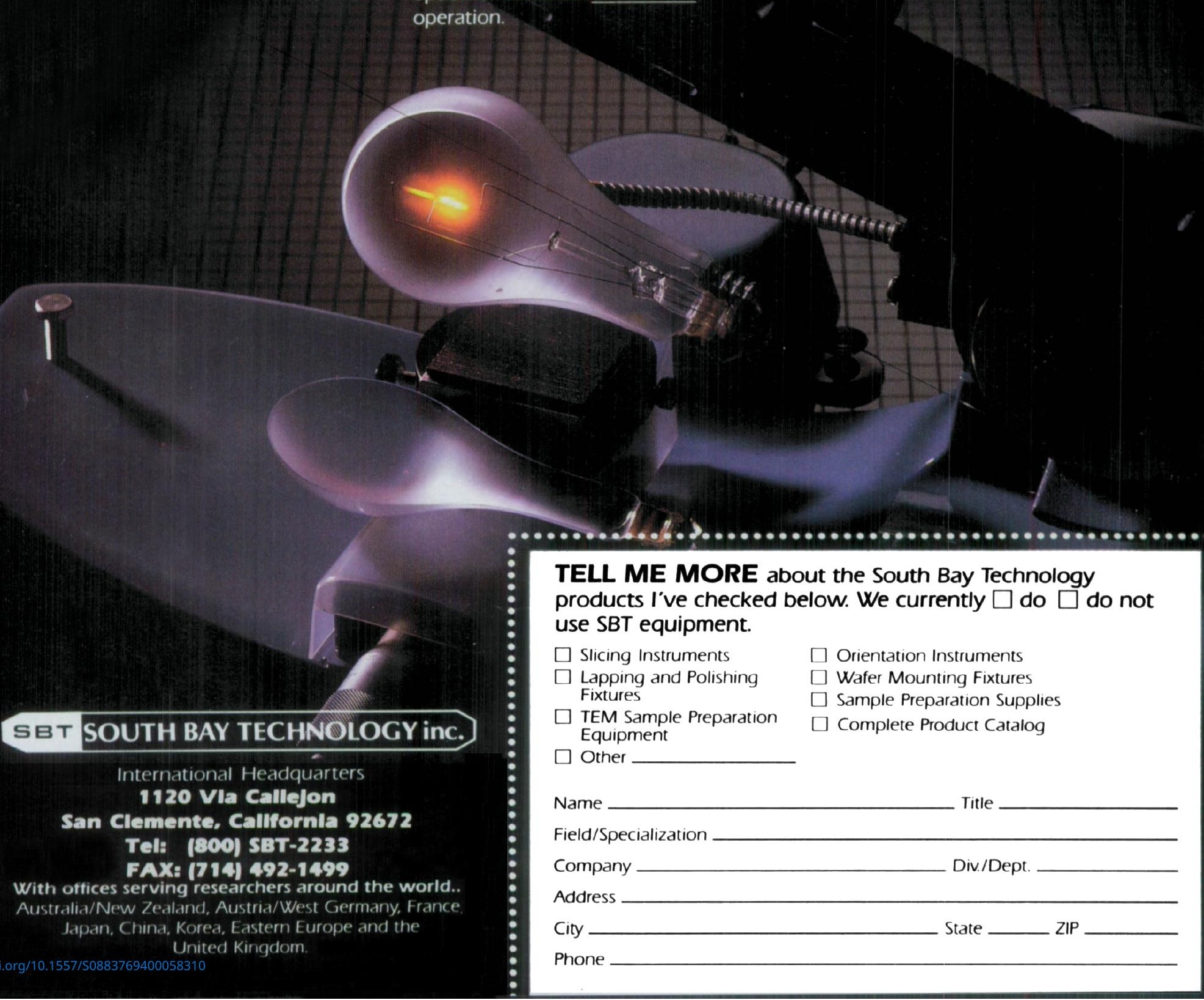




\section{The art of texture analysis

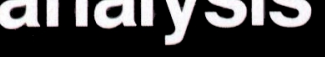

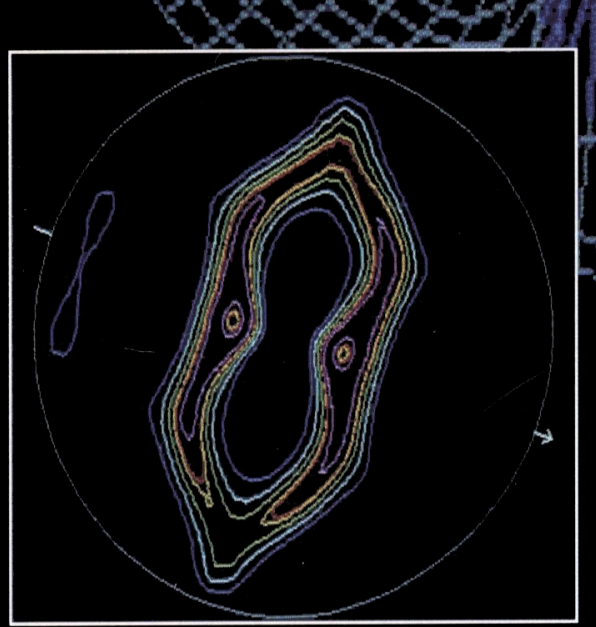

Siemens new 3 D

software - is the

elegant-solution to

- preferred onientation-

problems in

materials science.

\section{Siemens ... the company you can believe in.}

Please visit Booth No. 910-911 at the MRS Show in Boston, November 27-29, 1990.

Worldwide Contact: Siemens AG, Analytical Systems E 689 • D 7500 Karlsruhe 21 • P.O. Box 21 1262 • Federal Republic of Germany • Tel. (0721) 595-4295

In USA \& Canada contact Siemens Analytical X-Ray Instruments, Inc., a joint venture of Siemens \& Nicolet

6300 Enterprise Lane $\cdot$ Madison, WI 53719-1173 - Tel (608) 276-3000 • FAX (608) 276-3015 